\title{
Fossil amber reveals springtails' longstanding dispersal by social insects
}

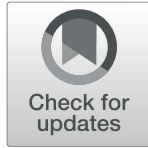

Ninon Robin ${ }^{*}$ (D), Cyrille D’Haese ${ }^{2}$ and Phillip Barden ${ }^{1,3}$

\begin{abstract}
Background: Dispersal is essential for terrestrial organisms living in disjunct habitats and constitutes a significant challenge for the evolution of wingless taxa. Springtails (Collembola), the sister-group of all insects (with Diplura), are reported since the Lower Devonian and are thought to have originally been subterranean. The order Symphypleona is reported since the early Cretaceous with genera distributed on every continent. This distribution implies an ability to disperse over oceans, however symphypleonan Collembola have never been reported in marine water contrary to other springtail orders. Despite being highly widespread, modern springtails are rarely reported in any kind of biotic association. Interestingly, the fossil record has provided occasional occurrences of Symphypleona attached by the antennae onto the bodies of larger arthropods.

Results: Here, we document the case of a $\sim 16 \mathrm{Ma}$ old fossil association: a winged termite and ant displaying not some, but 25 springtails attached or in close proximity to the body. The collembola exhibit rare features for fossils, reflecting their courtship and phoretic behaviours. By observing the modes of attachment of springtails on different arthropods, the sex representation and ratios in springtail antennal anatomies in new and previously reported cases, we infer a likely mechanism for dispersal in Symphypleona. By revealing hidden evidence of modern springtail associations with other invertebrates such as ants and termites, new compelling assemblages of fossil springtails, and the drastic increase of eusocial insects' abundance during the Cenozoic (ants/termites comprising more than a third of insects in Miocene amber), we stress that attachment on winged castes of ants and termites may have been a mechanism for the worldwide dispersal of this significant springtail lineage. Moreover, by comparing the general constraints applying to the other wingless soil-dwelling arthropods known to disperse through phoresy, we suggest biases in the collection and observation of phoretic Symphypleona related to their reflexive detachment and infer that this behaviour continues today.

Conclusions: The specific case of tree resin entrapment represents the (so far) only condition uncovering the phoretic dispersal mechanism of springtails - one of the oldest terrestrial arthropod lineages living today.
\end{abstract}

Keywords: Springtails, Dispersal, Phoresy, Symphypleona, Social insects, Dominican amber

\footnotetext{
*Correspondence: ninonrobin23@gmail.com

'Department of Biological Sciences, New Jersey Institute of Technology,

Newark, NJ, USA

Full list of author information is available at the end of the article
}

(c) The Author(s). 2019 Open Access This article is distributed under the terms of the Creative Commons Attribution 4.0 International License (http://creativecommons.org/licenses/by/4.0/), which permits unrestricted use, distribution, and reproduction in any medium, provided you give appropriate credit to the original author(s) and the source, provide a link to the Creative Commons license, and indicate if changes were made. The Creative Commons Public Domain Dedication waiver (http://creativecommons.org/publicdomain/zero/1.0/) applies to the data made available in this article, unless otherwise stated. 


\section{Background}

Dispersal is essential for terrestrial arthropods living in discontinuously distributed habitats. However, acquiring dispersal features (e.g. wings) may have significant costs, such as reducing the foraging efficiency of animals living in confined microhabitats (e.g. soil). In most insects, these conflicting requirements have been met through ontogenetic partitioning and the acquisition of holometaboly, allowing for soil-dwelling larvae, whereas dispersal is performed by the winged adults [1]. For wingless arthropods, the adaptive challenge of reaching new microhabitats is even greater and has led to phoretic adaptations, particularly in some arachnid groups (mites, pseudoscorpions [2, 3]).

Although considered widespread, phoresy - cases of organisms attaching onto others for the implied purpose of dispersal - is poorly understood relative to other interspecific associations [4]. As an instance of commensalism, the definition of phoresy has been revised over time to become - following the case of mites - an association in which an organism receives an ecological or evolutionary advantage by migrating from its natal habitat while attached to an interspecific host for some portion of its lifetime [4-6]. The ambiguous nature of phoresy is rooted in the difficulty assessing and quantifying putative advantages over generations, whereas observable food sources (present in other commensalisms) are generally viewed as evidence of fitness improvement. Consequently, phoretic behaviors are often lent to associations between small organisms and larger mobile ones that show no evidence for other beneficial purposes. This holds especially true when trying to interpret the fossil record [7-9].

Springtails (Collembola) are entognathans, the sistergroup of all other insects, and are reported since the Lower Devonian $[10,11]$. The ancestral ecology of entognathans is thought to have been subterranean; the soil environment is suspected to have acted as an intermediate medium between water and air in the evolution of arthropods [12]. Today, springtails, which have a decisive impact on global soil microstructure and plant litter decomposition [13], are widely distributed on every continent, including Antarctica $[14,15]$. As the common name suggests, their abdomen usually displays a jumping apparatus (the furcula) used to escape general predators. Because furcula motility is not sufficient for dispersal, modern springtails are only thought to disperse with soil particles as "aerial plankton" and by water for long-distance transportation [16-18]. The latter, rather unexcepted for the group, was occasionally observed and confirmed by experiments for two of the four springtail orders (Poduromorpha and Entomobryomorpha) [17, 19, 20]. Despite their geographical and ecological ubiquity, modern springtails are very rarely reported to be engaged in biotic associations.

In addition to a few Paleozoic reports [10, 21], fossil springtails are reported from Cretaceous and Cenozoic amber deposits, in which they have occasionally been documented attached onto other invertebrates. Cases correspond to members of the order Symphypleona attached to harvestmen (Opiliones) and a false blister beetle (Oedemeridae) from the Eocene in Baltic amber $[22,23]$, as well as a mayfly (Leptophlebiidae) in Mioceneaged Dominican amber [24]. These springtails exhibit antennae either grasping arthropod limbs or pointing toward a potential surface of attachment, implying they were grasping onto these other arthropods while alive. This repeated fossil association has been argued to have no observed modern counterpart [22, 23].

Here, we document the case of a $\sim 16 \mathrm{Ma}$ old fossil association: a winged termite and ant with 25 springtails attached or positioned close to the body. The collembola exhibit rare features for fossils, reflecting their courtship and phoretic behaviors. By observing (1) the positions and modes of attachment of springtails on different arthropods, (2) their sex representation and (3) ratios in springtail antennal anatomies in new and previously reported cases, we infer an attachment process for dispersal in symphypleonan springtails. By revealing hidden evidence of modern springtails associated with other invertebrates such as ants and termites, new cases of fossil inclusions of Symphypleona and termites, and pointing out the drastic increase of eusocial soil insects' ecological impact over Cenozoic (comprising more than a third the of the total insect inclusions in Miocene amber), we infer that association with winged castes of ants and termites may have been a mechanism for the worldwide dispersal of these springtails. Finally, by comparing the general constraints applying to the other soil-dwelling wingless arthropods known to disperse through phoresy, we evidence - aside from the specific case of tree resin entrapment - strong biases against the collection and observation of phoretic Symphypleona and hypothesize that, although unreported, this behaviour remains a common modern occurrence.

\section{Results}

(a) Systematic Palaeontology

Order Symphypleona Börner 1901 [25]. Suborder Sminthuridida Börner 1986 [26]. Superfamily Sminthuridoidea Börner 1906 [27]. Family Sminthurididae Börner 1906 [27].

Genus Electrosminthuridia gen. Nov. Robin, D'Haese and Barden.

\section{Type species}

Electrosminthuridia helibionta sp. nov. Robin, D'Haese and Barden. 


\section{Diagnosis}

Based on male. The genus is distinguishable from other genera by combination of the following characters: antennae length about 1,8-2,5x as long as cephalic length; third and second antennomeres modified in males into a neat clasping organ, with a moderate angular b1 bearing at least one neat spiny setae, and a round moderate c3; fourth antennomere about $60 \%$ in male and $50-60 \%$ in females of the total antenna length, subdivided in 8 to 9 subsegments. Furcula: mucro short, very thin and tapering, ratio of mucro, dens, manubrium comparable to 1,0:1,2:0.9.

\section{Derivation of name}

The genus-group name is a combination of Ancient Greek,

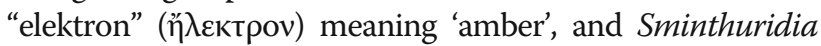
Massoud \& Betsch, [28], extant genus comparable in diagnosis. The gender of the name is neutral (unstated for Sminthuridia Massoud \& Betsch [28]).

Electrosminthuridia helibionta sp. nov. Robin, D'Haese and Barden.

(Figs. 2, 3d, SM1-2)

\section{Diagnosis}

As for the genus.

\section{Derivation of name}

The specific epithet, considered as an adjective, is a combination from the ancient Greek "helix" (ह் $\left.\lambda_{1} \xi\right)$ describing "something twisted or spiral" and "biont", the common internationally used suffix referring to living things. It refers to the species ability to coil its antenna around a surface to live as an epibiont of its larger host/partner.

\section{Type material}

Holotype, AMNH DR-NJIT001_sk (ô, Fig. 1, 2f), complete, dorsoventrally exposed, and 3 similarly exposed paratypes: AMNH DR-NJIT001_ss ( ${ }^{\lambda}$, Fig. 1, 2e), AMNH DR-NJIT00 1_sj (o, Fig. 1, 2f), and AMNH DR-NJIT001_sm (q, Fig. 1). Five individuals (AMNH DR-NJIT001_si-m) including the holotype were extracted from main inclusion for detailed visualization.

\section{Type locality and age}

Miocene amber of the Dominican Republic, La Cumbre.

\section{Description}

See Additional file 1.

\section{(b) Fossil association}

The ant/termite-springtail associations are preserved in a rectangular piece of highly transparent amber trimmed to $1.7 \times 2.0 \mathrm{~cm}$, also containing a male cecidomyiid midge and a chalcidoid wasp. The colonized termite (AMNH DRNJIT001_a; Fig. 1) has been identified as a Coptotermes hirsutust Krishna \& Grimaldi [29] (Rhinothermitidae). The ant corresponds to a dolichoderine male (AMNH DRNJIT001_b; Fig. 1). The ant and the termite are complete and inversely oriented, both corresponding to alate reproductives. Among included springtails, 25 correspond to the sminthuridid Electrosminthuridia helibionta sp. nov. and one to an Isotomida (Entomobryomorpha; AMNH DRNJIT001_sq, Fig. 1b).

One sminthuridid is found attached onto an ant leg, and seven on various regions of the termite body. The 18 other springtails are variously distributed around both of these large insects revealing key anatomical details. AMNH DRNJIT001_sa (Figs. 1, 2a) is found on the termite left antenna with its body, head and, antenna clearly pointing toward the tenth flagellomere. Three individuals are located on the termite left hindwing (AMNH DR-NJIT001_sc, r) and forewing (AMNH DR-NJIT001_sd) membranes (Figs. 1, 2b), whereas three others are clearly restricted to the anterior margin of the termite wings. Two of them (AMNH DR-NJIT001_sb, z; Figs. 1, 2a, d) are laterally orientated onto the sclerotized anterior margin of the left hindwing (close to the wing scale) and right forewing (distally), their right and left antennae respectively overlaying this margin. This lateral posture is observed in the attachment of the single specimen found clasping onto the ant, with the left antenna overlaying the first tarsi of the ant hind leg (AMNH DR-NJIT001_sv; Figs. 1, 2c). Individual AMNH DR-NJIT001_se (Figs. 1, 2g), located on the termite proximal right hindwing margin, shows a position even more intricately attached to the host body. Indeed, their fourth antennomere is distinctly enveloping the margin and the springtail buccal cone applied onto that surface, demonstrating a specific attachment process. Slightly distally on that margin, three other individuals are preserved in a distinct successive row, (AMNH DR-NJIT001_sf-h; Figs. 1, 2g) illustrating a linear series of detached individuals, probably trapped in the resin inflow before hardening. More generally, 14 other sminthuridids are floating in the resin close to the termite (AMNH DR-NII T001_si-p, s, w-y; Figs. 1, 2e) and ant (AMNH DR-NJIT001_ st-u; Fig. 1) some in clusters up to three individuals similarly preserved in a straight line (Fig. 2f). An unfolded furcula is visible in 11 individuals and obscured in all other sminthuridid inclusions. One specimen clearly exhibits the first undisputable clasping organ in the fossil record (Fig. 2f, 3d, SM12), a synapomorphy of Sminthurididae and major innovative feature allowing their specific mating behaviour. This organ, specific to males, is involved in a "dancing" courtship behaviour of sminthuridids, the male dragging the female onto the spot of his sperm drop by grasping her antennae [30, 31].

A total of 51 amber pieces from the same La Cumbre amber containing termite inclusions were screened for the presence of springtails. This piece was the only one 


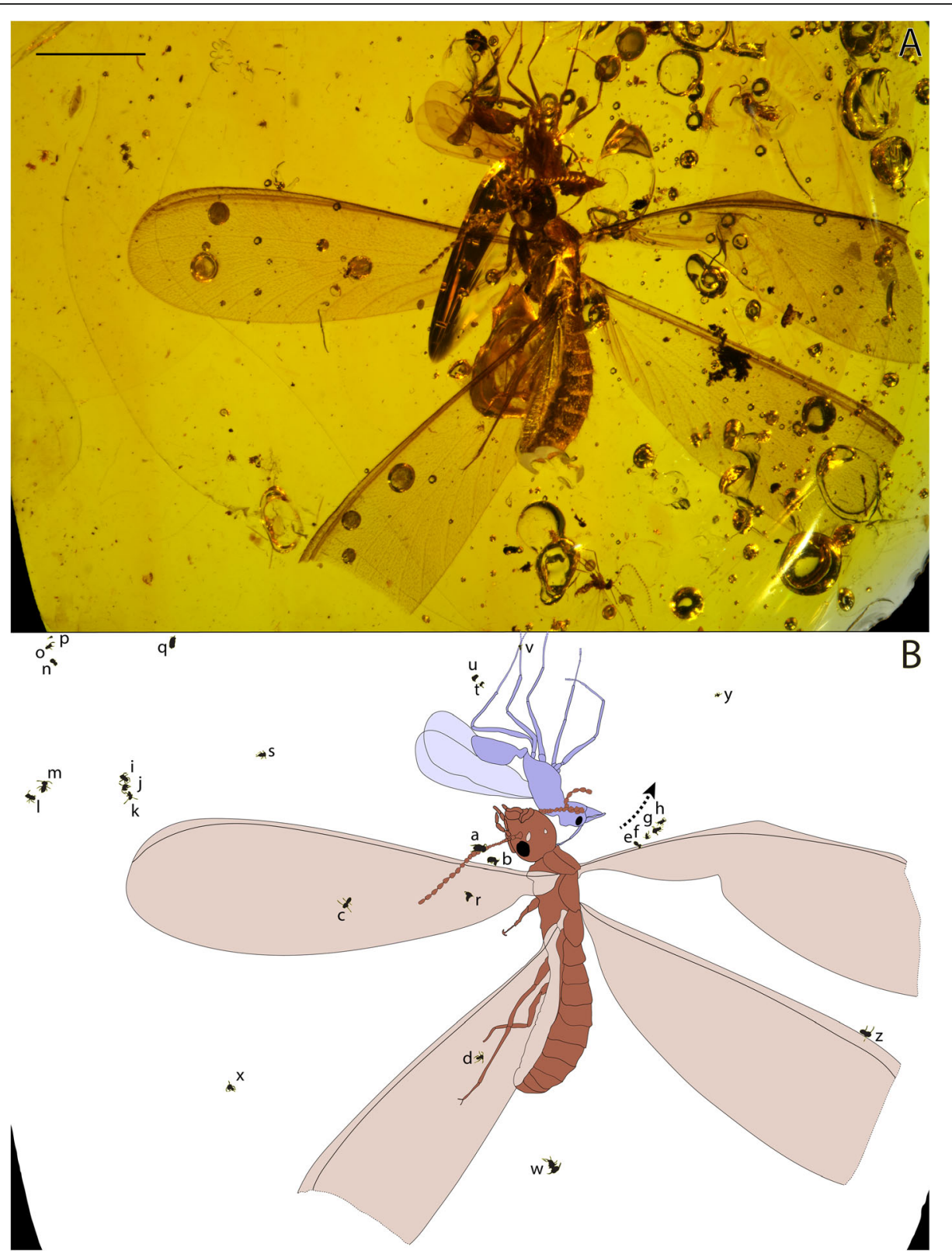

Fig. 1 Distribution of springtails on termite and ant hosts within 16 Ma old Dominican amber. a Amber specimen; $\mathbf{b}$ Illustration showing the location of springtails on social insects (AMNH DR-NJIT001_sa-z). Arrow $=$ inflow of the tree resin before consolidation. $5 c a l e ~ b a r=0.5 \mathrm{~cm}$. Photograph and interpretative drawing, N. Robin \& P. Barden

displaying springtails, corresponding to less than $2 \%$ of our observed sampling.

\section{Discussion}

\section{(a) "Hitchhiking" for dispersal}

Remarkably, despite tens of thousands of known insect fossil inclusions, our report corresponds to about $6 \%$ of all the previous occurrences of individual springtails reported in Dominican amber and consists of two taxa out of twelve described in total [32-34]. As this association is unique among many comparable specimens of termites from La Cumbre, it cannot represent the general abundance of these springtails in termites' environments but must correspond to a more specific biotic explanation.

Other symphypleonan fossil associations are known from amber, beginning with two cases of Eocene harvestmen legs supporting up to five individuals arranged in a row and clasped by the antennae (Cholewinsky pers. comm. in [22]; Fig. 4). While the springtails were differently positioned (either facing the leg or facing away from it), they all show 

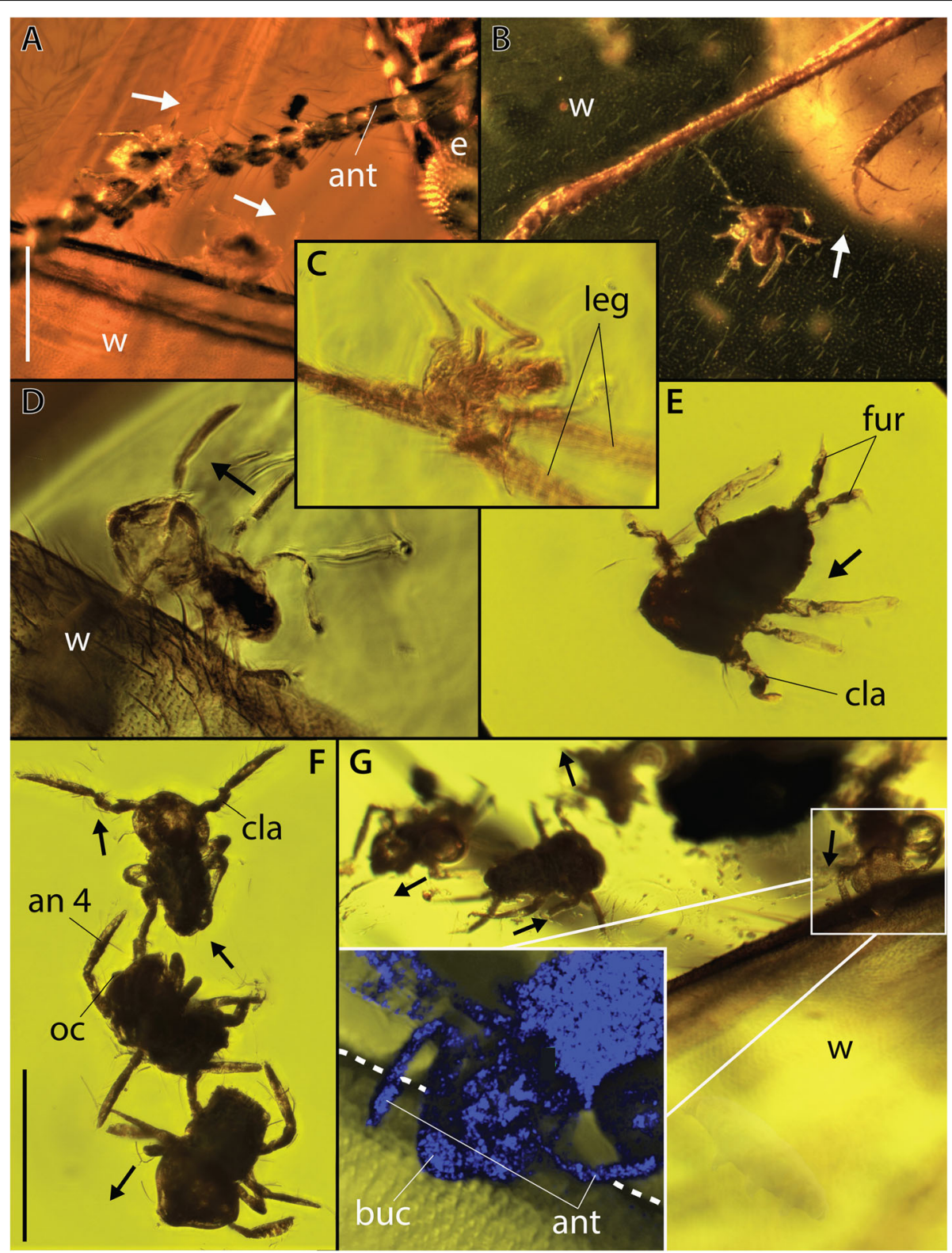

Fig. 2 Springtails attached onto a termite and an ant from 16 Ma old Dominican amber. a AMNH DR-NJIT001_sa-b respectively grasping onto the termite (AMNH DR-NJITO01_a) left antenna and left anterior wing costal margin. b AMNH DR-NJITO01_sd on the termite left posterior wing. $\mathbf{c}$ AMNH DR-NIIT001_sv attached to the posterior mid-leg of the ant (AMNH DR-NJIT001_b). d AMNH DR-NJIT001_sz found on the termite right posterior wing costal margin. e AMNH DR-NJIT001_sS showing furcula. f AMNH DR-NJIT001_si-k displaying respectively clasping organ (AMNH DR-NJIT001_sk, male), segmented antennomere 4 and ocelli (AMNH DR-NJIT001_sj). g AMNH DR-NJIT001_se-h found onto/close to the right anterior wing costal margin, with close-up on AMNH DR-NJIT001_se attachment to the margin using antennae and buccal cone. an = antennomere 4, ant = antennae, buc = buccal cone, e = eye, fur = furcula, oc= ocelli, cla = clasping organ, leg =leg, $w=$ wing. Arrows indicate the anterior of springtail individuals, Dashlines outlining margin costa. A-B, stereoscope images; C-G compound microscope and confocal reflectance images. Scale bars $=0.5 \mathrm{~mm}(\mathrm{~A}-\mathrm{B}) ;(\mathrm{C}-\mathrm{G})$. Photographs, N. Robin

antennae distinctly bent toward this appendage, suggesting antennae were initially secured to it. The resulting position was interpreted as their immediate detachment following resin entrapment [22]. Associations with winged insects are described from attachments on the forewing base of a mayfly (Miocene [24]) and the leg of an false blister beetle
(Eocene [23]; Fig. 4c). In the case of the beetle association, antennae were implicated, as were the mouthparts which may have grasped onto the leg surface (or perhaps tibial setae, [23]). Thus, all previous cases of preserved attachment of springtails (excluding that of the mayfly association) were described from smooth cylindrical legs. The 


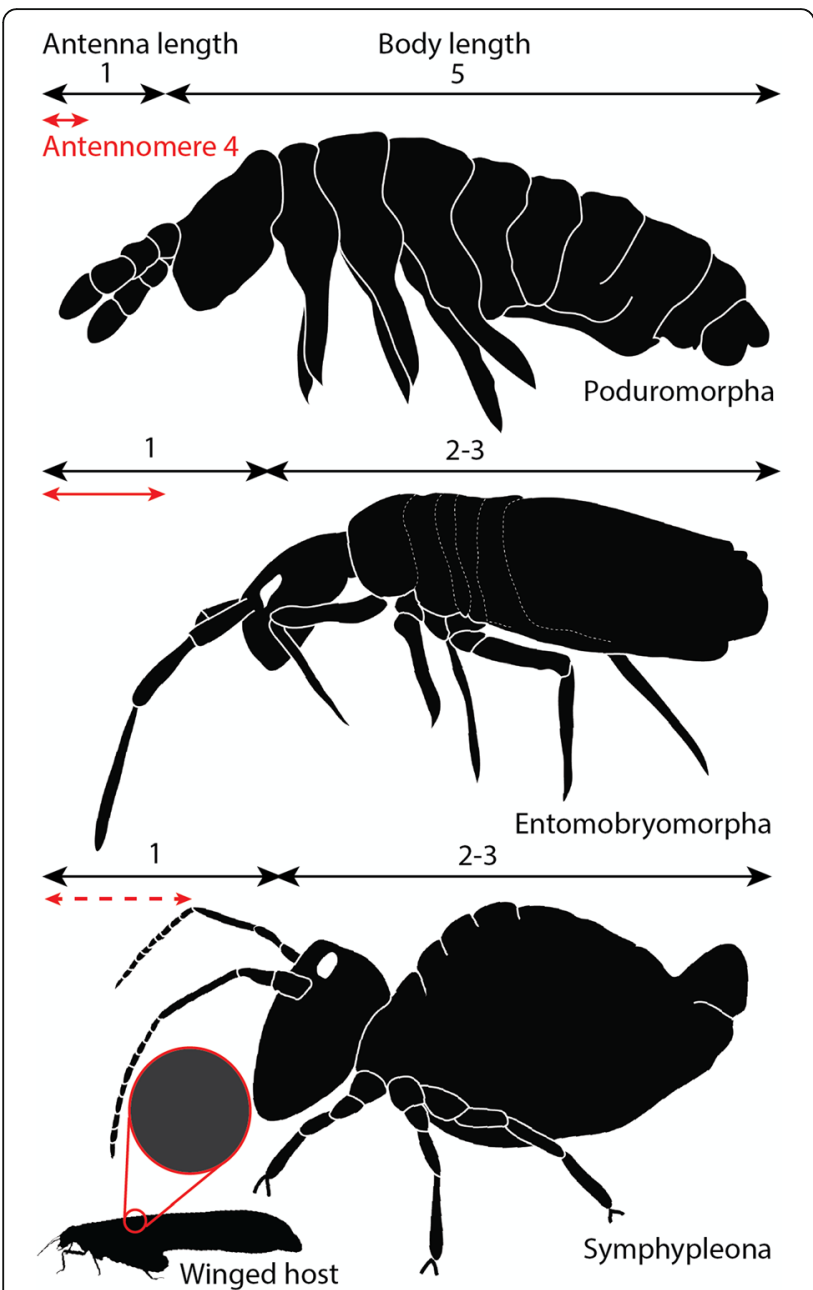

Fig. 3 Body proportions in Collembola orders and suitability for phoretic grasping. Arrows represent anatomical lengths; figures correspond to relative anatomic ratios. Grey structure represents cylindrical support for antennal grasping on host. Dashed-line lengths represent sub-segmentation of the antenna. Neelipleona possess highly reduced antennae, they are not represented in this comparison. Drawing, N. Robin

associations here reveal springtails with a positioning attachment preserved on novel structures consisting of insect antennae and wing margins. In those cases, we observe that the attachment is also achieved by rolling up of the fourth antennomere around termite antennae/sclerotized wing margins, implicating this structure in the phoretic ability of the springtails. Possible variations in grasping mechanisms have been briefly addressed, stressing the attachments of both a long-antennomere species (Sminthurus longicornist) to a $25 \mu \mathrm{m}$-thin leg, and that of a medium-antennomere species (S. sp.) to a $100 \mu$ m-thick leg [22, 23]. The herein case confirms these possible variations revealing the attachment of a much smaller species with quite short antennomeres grasped onto $20-40 \mu \mathrm{m}$ thick structures. We stress that this behaviour must have been even more dependent on antenna/body lengths. Indeed, in Poduromorpha and even more in Neelipleona morphotypes the antenna/body length ratio is less than 1:3 (Fig. 3). And if many Entomobryomorpha possess longer antennae - reaching a third to half of their total length - their limited antennal subdivision would preclude any antennal attachment that could support their total body weight (see [42], Fig. 3). Attachment efficiency may be restricted to symphypleonan morphotypes that correspond to a short bulbous body with (1) antennae reaching a third to half of the body length and a (2) fourth prehensile antennomere with subdivisions consisting at least $1 / 3$ of the antenna length (Fig. 3). As an example, in E. helibionta sp. nov. the fourth antennomere is divided in eight sub-segments representing in total $60 \%$ of the total antennal length. Variations in length and subdivision of fourth antennomere among Symphypleona might have driven specificities in host selections/attachments, their increase probably contributing to more generalist behaviours. Our observations also confirm the involvement of mouthparts as a secondary attachment element utilized in grasping surfaces or acting as an abutment.

Antennae appear to be key for phoretic attachment, however they are subject to significant sexual dimorphism. Unlike other Symphypleona, the second and third antennomeres of male Sminthuridoidea are modified into a clasping organ; this structure is preserved in $E$. helibionta nov. sp. However, among 25 individuals, only three males (AMNH DR-NJIT001_ss, si; Fig. 2e-f) could be identified in the inclusion. Could this disparity in sex representation have a biological underpinning? Phoretic behaviours restricted to females have been reported in other phoretic wingless arthropods. Aggregations of female mites and pseudoscorpions, sometime identified as gravids, were reported in extant fauna competing for various hitchhiking hosts (harvestmen, beetle, diptera, frog) [43-46]. From laboratory experiments, Zeh \& Zeh [1] demonstrated a female bias in phoresy by pseudoscorpions that increases over time, and with mated females exhibiting a slightly higher rate of phoresy than unmated ones. Given pseudoscorpions' ecological proximity and ametabolian life cycle, this - rather unexplained bias - could relate to that of phoresy among springtails observed here. The amber piece contains four distinct flying insects, some caught with wings still open, which is suggestive of an arboreal capture in the tree resin for which all trapped sminthuridids would have detached from the ant/termite association, as illustrated also by unfolded furculae. However, the presence of one Isotomida (Entomobryomorpha) in the inclusion, could advocate for a trapping in amber close to the soil, implying the possible trapping of a few non-associated sminthuridids. Given this taphonomic limit, we cannot definitively conclude on a discrepancy in sex representation in this association. Besides, we note that comparable 


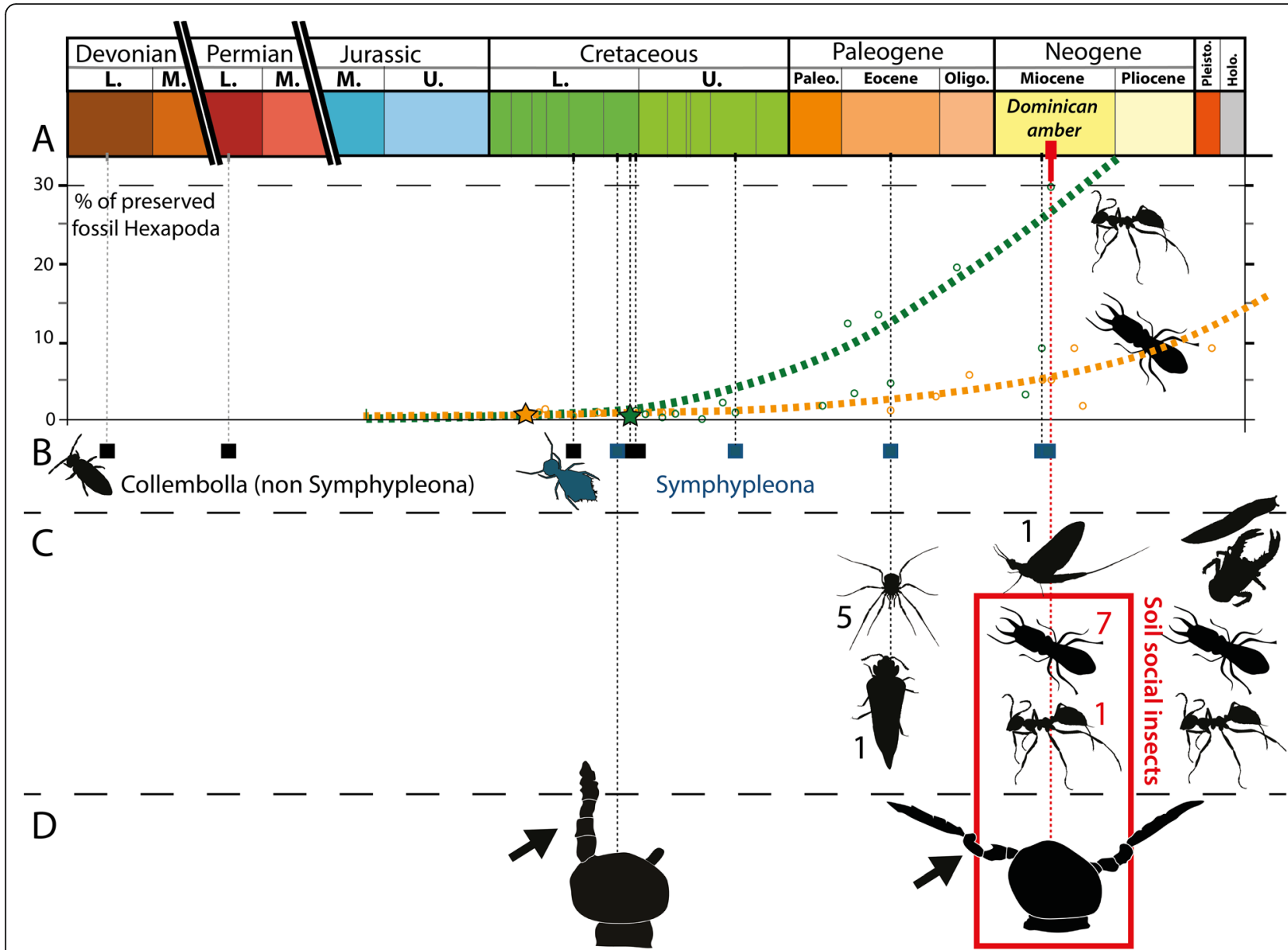

Fig. 4 Abundance of ants and termites, collembola body fossils, phoretic behaviors and clasping organs over time. a Evolution of the percentage Isoptera [orange] and Formicidae [green] among other Hexapoda found from fossil amber and compression-preservation deposits. Based on abundances provided in Engel et al. [35] for Isoptera and Grimaldi \& Agosti [36], LaPolla et al. [37] for Formicidae. b Body fossils of Collembola over time $\mathbf{c}$ Associations of Collembola onto other organisms over time, including modern cases with slugs, decapods, ants, and termites. Figures represent the number of attached springtail individuals. $\mathbf{d}$ Clasping organs described from fossil ambers. Stars = first fossil occurrences; squares = body fossils; frame = case described here. Arthropod silhouettes from PhyloPic [38-41]

disparity in sex representation have been suggested for the modern symphypleonan Sminthurides in general sampling context [47].

While migration strategies in springtails are poorly understood, they have been observed to occur through four vectors: windborne, pedestrian, rafting, and wind propelled on water surface [18]. Because Collembola are highly susceptible to desiccation, it is highly unlikely they are capable of moving over oceanic distances through aerial movements, favouring recently accepted water dispersal confirmed by experiments $[17,19]$. However, the evidence so far of waterborne dispersal only applies to Poduromorpha and Entomobryomorpha; as well as for large "swarm" pedestrian migrations [17, 19, 20, 48, 49]. Symphypleona have so far only been caught in air (up to $3350 \mathrm{~m},[18,50]$ ) and, as strictly terrestrial and freshwater inhabitants, there is no evidence that they could maintain themselves in association with brackish water [51]. However, Symphypleona, which extends into Spanish amber dated to the Lower Cretaceous [52], display many recently diverged clades (e.g. genera Sminthurinus and Sminthurides) on every continent. This present-day distribution suggests the existence of additional mechanisms for significant dispersal. The type of phoresy evidenced herein from the fossil record may have facilitated this long-distance dispersal.

\section{(b) Springtails and phoresy}

Previous fossil reports all noted the absence of modern phoresy in springtails, highlighting a questionable discrepancy (lack of modern records vs extinct behaviour, [22, 23]). Given the introduced biases affecting the identification of phoresy among commensals, we disagree with that first appraisal and uncover some, so far, hidden cases.

In fact, springtails have been reported to have associations with a diverse assortment of invertebrates, although the 
nature of the associations has not been determined. A frequently documented case corresponds to the repeated observation of termitophile and myrmecophile inquiline springtails. Different genera of cyphoderid springtails have been observed clinging to the head and back of soldiers and queen termites within nests ([53-55], Fig. 4c). In those cases, specialized sucking mouthparts, their location on soldiers' heads and their posture - drooping toward the termite labrum - suggest that springtails obtain small meals from trophallactic soldier-worker food transfers. Cyphoderids have also been reported attached to reproductive alate ants (both females and males, [56]). Food-supply commensalism has been suggested from the observations of springtails (both Entomobryomorpha and Symphypleona) on Palearctic slugs, feeding on their mucus ([57], Fig. 4c). But springtails are also curiously reported as commensals of the shells of hermit crabs of tropical land environments ([58-64], Fig. 4c). These associations were reported from about a hundred of specimens from Mexico, New-Guinea, the Caribbean (Guadeloupe, Dominican Republic, Saint Croix). In 2005, we observed 80 individuals caught from 7 hermitcrabs and sands from different Martinican beaches (Anse Trabaud, NE of Les Salines, Grand Macabou, Presqu'ile de la Caravelle) evidencing the relative commonness of these associations within the pantropical range of these terrestrial crustaceans (Coenobitidae). The biological purpose of these associations has been addressed as a possible trophic inquilinism [64] linked to consumption of host food remains or feces; but the actual springtails' (Coenolatidae) location inside shells or their feeding activity was never observed. Alternatively, these associations characterize specimens collected from beach environments into which the backshore microhabitats of springtails are discontinuously distributed, requiring alternative dispersal options. Associated individuals consist mostly of females and juveniles whereas males represent about $10 \%$ of documented samples; which could be linked to an unequal sex distribution in species or a difference in sex involvement when associations relate to transport. These reports of poorly understood commensalisms with other invertebrates argue for the existence of actual phoretic-like behaviours in modern Collembola.

No modern Symphypleona is known to perform attachment to cylindrical structures by use of antennae. It has been suggested that this behaviour could have been restricted to extinct lineages of Symphypleona having especially elongate flexible antennae [22]. From the variability of antennae exhibited here, we exclude this possibility. In addition, the herein fossil association reveals the nature of Symphypleona reactions to disturbances. The fossil inclusion preserves an alate termite that could not begin to fold its wings when trapped, implying an almost immediate capture in the resin. In that meantime, most springtails managed to get completely or partially detached of their host revealing the reactive mobility of the antennae, perhaps comparable to that of the furcula. A reflexive detachment may explain the apparent absence of modern phoretic Symphypleona based on modes of collection in the field. Insects and arachnids are collected most frequently by direct immersion in ethanol before being prepared for collections. It is very likely that given their superficial attachment and quick detachment system, phoretic springtails may detach from hosts in ethanol or even before immersion, effectively removing link between host and commensal (see Fig. 5a for comparison with other wingless phoretic arthropods). The tiny proportions of phoronts (as shown in this fossil case) relative to all types of soil arthropod hosts (including ants and termites) would have impeded the discovery of modern representatives even when initially collected and kept in alcohol with the host (Fig. 5b). In this context, the immediate embedding of springtails onto insects by tree resin would characterize a unique scenario enabling the preservation of these associations, making the fossils of high significance for documenting this phenomenon.

\section{(c) Collembola evolving with social insects}

Three of the four orders of modern springtails are reported from termite and ant nests [55, 65-67]. This includes cyphoderids primarily described as nests inquilines as well as direct commensals of termites and ants [52-56, 67]. Thus, despite constraints in collecting modern phoretic springtails, other reported cases suggest significant relationships with social insects. Moreover, we report paleoecological insight that further bolsters links between springtails and social insects. Based on an initial screening of more than 1300 inclusions within rough Cambay amber from the Lower Eocene (54 $\mathrm{Ma}$ ) of western India, we report only two Symphypleona. Those two individuals, representing different genera, are both located a few millimeters from a single alate termite.

Today, ants and termites together comprise a significant component of many terrestrial ecosystems. The biomass of termites is estimated to be approximately equal to that of humans [68] and in tropical localities, termites and ants together may outweigh all vertebrates and all other insects combined [69]. It is possible to trace the "rise" of soil-dwelling social insects from their first appearance in the fossil record to their remarkable ecological impact today. The termite and ant fossil records extend to the Lower Cretaceous of Russia (Berriasian) and Charentese-Burmese ambers (Albian, Fig. 4a), respectively. In the Cretaceous, ants and termites never comprise more than $2 \%$ of all fossil hexapods by locality $[70,71]$. This changes markedly by the Cenozoic. In Dominican amber, termites make up to $6 \%$ of inclusions while ants represent $\sim 30 \%$ of all hexapods; social insects represent more than $1 / 3$ of the total entomofauna at that time (Fig. 4a). As they constitute the vast majority of soil 


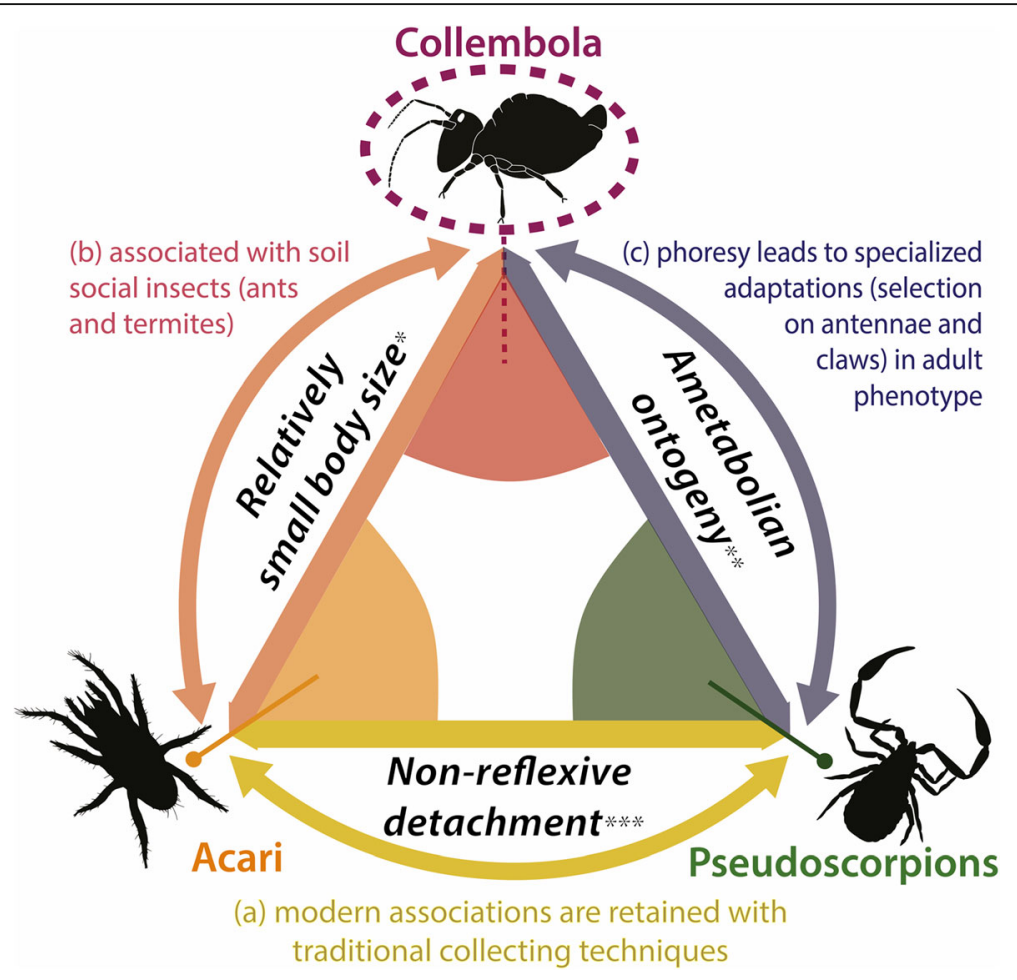

Fig. 5 Morphological, ontogenetic and behavioural constraints for phoretic strategies among apterous soil-dwelling arthropods. Three criteria shape the phoretic interactions of apterous arthropods with larger hosts, introducing the new case of collembola (Symphypleona). Cases of collembolan (symphypleonan) phoresy correspond with a specific set of conditions that are not met by other phoretic soil-dwellers. Criteria support the heterogeneous nature of reports of these different associations in modern instances, with the so far totally unreported case of modern Symphypleona associations. ${ }^{*}$ much smaller relative to all types of other soil arthropods; ${ }^{* *}$ no specific phoretic lifestage during ontogeny; ${ }^{* *}$ of claws or mouthparts

insects, termites and ants stand as an immediate model for widespread biological interactions in springtails.

Though they span a range of ecologies (soil, leaf litter, canopy), ant lineages are primarily soil or surface dwelling [72]. For Blattodea - ie. cockroaches and termites modern groups live in the superficial soil including litter and in wood logs, corresponding to their ancestral ecology $[73,74]$. The host termite identified here, Coptotermes is also distinctly subterranean [73-75]. Advanced levels of sociality are documented in fossil stem-ants as early as the mid-Cretaceous $[57,58]$ and the early Mesozoic in termites [50,51], implying that soil nests were present early in the emergence of these two taxa.

Consequently, various springtail families would have been confronted with the fast-increasing prevalence of eusocial insects from the mid-Cretaceous onwards, eventually leading to advantages of living close or inside their nests, as reported for most orders of springtails ([55, 65-67], Fig. 4b). Termito/myrmecophile ancient behaviours have previously been suspected for other Dominican amber springtails (cyphoderines, [32]).

Living in close proximity to termites and ants would have provided significant benefits for springtails. An initial termito/myrmecophile behaviour could then act as a catalyst, providing opportunity for the evolution of more specialized associations. This type of specialization to eusocial environment is also observed in other groups of early diverging hexapods like bristletails (Thysanura), which are reported as myrmecophiles [76] but also as direct commensals climbing on large ant larvae at colony migration [77]. Thus, beside termito/myrmecophile behaviours, associations with eusocial insects appear at least twice in the evolution of springtails: in cyphoderines (Entomobryomorpha, Paronellidae) for apparent feeding and in Symphypleona for (primary or secondary) dispersal. From both fossil and modern examples, we infer that social insects have acted as symphypleonan dispersal agents. The phoresy would have been enabled through hitchhiking on alate termite/ant adults at the time they reach the leaf litter to begin their nuptial flights. Comparable to many symphypleonan genera, Coptotermes has distributed onto every continent with diversification since just the Miocene [78], implying its strong ability for overseas dispersal. Modern subterranean termite flights are known to reach $900 \mathrm{~m}$ over a single take-off above very large water masses (e.g. the Mississippi river, [79]). While these relatively short distances alone do not explain the worldwide distribution 
of termites, lineages that exhibit comparable timing of diversification and distribution over continents could explain the dispersal process of sminthurid clades. The grasping ability of Symphypleona would have been enhanced by the elongation/segmentation of the fourth antennomere. This derived feature may have enabled the hitchhiking of other soil surface inhabitants (toward more or less efficient dispersal), as observed in other fossil examples (Fig. 4c).

From both fossil and modern cases, soil-dwelling social insects show an obvious trend for biotic associations with smaller apterous arthropods. Indeed, modern mites (both parasitiforms and acariforms) are known for living in ant nests, with phoretic nymphs found on extant ant alates, as well as army ant workers [80-82]. These nymphs, called hypopi, correspond to a non-feeding stage of mite ontogeny, specialized for phoresy. These associations have been reported twice as early as $44 \mathrm{Ma}$ (Mesostigmata; 56,57). If less described, termitophilous mites are also abundant [83-85], with at least eight (parasitiform and acariform) families detected from the study of only three subterranean termites (including Coptotermes) in various continents [86-90]. The small size of soil-dwelling social insects limits these associations, restricting phoresy to mites and other millimeter-sized organisms, such as springtails (Fig. 5b). Contrary to mites, the ontogeny of springtails displays no metamorphosis (ametabolism, [91]) and thus, no specialized stage to increase dispersal efficiency. It is therefore relevant that phoresy in this group appears in the adult-phenotype (through attachment structures) and primarily in lineages most pre-equipped for this kind of acquisition (Symphypleona). Springtails share this criterion with pseudoscorpions in which phoretic abilities are displayed by the adult phenotype as well, namely through adapted claws (Fig. 5b). In this regard, springtail phoresy compares with the selection constraints of the attachment strategy found in pseudoscorpions, applying within the host range found in mites, but controlled by a much more reactive behaviour, probably reflective of fast hexapod motility speed compared to that of most arachnid orders ([92], Fig. 5). Through their body proportions and antennae length, Symphypleona would have been primed for specialized phoretic behaviours among other springtail morphologies (Fig. 3). Limited understanding of modern counterparts impedes consideration of whether these phoretic behaviours could have shaped symphypleonan morphology beyond antennae.

\section{Conclusion}

Our results detail the existence of a new type of phoretic behaviour among wingless soil-dwelling arthropods. This behaviour would have been at the origin of the actual worldwide dispersal of symphypleonan springtails which have never been reported from marine water and therefore are unlikely to have followed long-range dispersal processes employed by other lineages. Our survey of hidden associations of springtails with larger organisms argue for their ability to establish generalist and specialized relationships with several hosts, although these are almost entirely unstudied. Fossil and modern occurrences support a connection between the appearance of phoresy among springtails and the increase of social insects' ecological impact over time. Their great abundance, small size, and social organisation including (1) soil castes of ants and termites sharing the early habitat of Symphypleona, and (2) winged castes dispersing to different microhabitats at mating, would have constituted a key vector for dispersal strategy in the springtails - one of the oldest living terrestrial arthropod lineages. This mode of phoresy refers to selection pressures applied onto the adult phenotype as springtails undergo no metamorphosis throughout their ontogeny, as in pseudoscorpions. Their potential range of host sizes is comparable with that observed for mites. However, springtails movement speed (as shown by the amber entrapment evidence) would argue for a system of detachment from the host so quick that traditional arthropod sampling methods have missed modern occurrences. We propose that these associations remain common in extant taxa, albeit hidden until alternative sampling techniques are employed.

\section{Methods}

The amber specimen hosting the association (AMNH DRNJIT001) originates from La Cumbre, Dominican Republic and is deposited at the Division of Invertebrate Zoology at the American Museum of Natural History. The amber has been trimmed and polished with a water-fed trim saw and Buehler EcoMet ${ }^{\text {ta }} 30$ grinder to improve imaging and reveal additional detail. Lower magnification $(1-2 \mathrm{x})$ extendedfocus photomicrographs were taken with a Nikon SMZ-18S through NIS Element D software. Higher magnification pictures were captured with a Nikon Eclipse TS2 compound microscope after immersion in glycerol. Reflectance images of springtails were captured with a Leica SP8 confocal scope (NIIT) and processed using the LAS X software. For systematics, we follow Derhaveng [93] for more inclusive ranks and Bretfeld [47] for subordinal classification. For generic assignment we build upon Massoud \& Betsche [28] which includes the most complete comparative work of secondary sexual characters in modern Symphypleona.

\section{Supplementary information}

Supplementary information accompanies this paper at https://doi.org/10. 1186/s12862-019-1529-6.

Additional file 1: Description of Electrosminthuridia helibionta sp. nov.

Acknowledgments

We thank Jorge Martinez and Keith Luzzi for facilitating access to specimens. Hukam Singh and David Grimaldi for access to Cambay amber specimens 
and proportions of arthropod inclusions. We are grateful to Viktor Baranov for identifying the associated gall midge. N. Robin wishes to thank L. Legender for discussion on taxa names. This work has been achieved along a Fulbright Visiting Scholar Program (National Program) of the FrenchAmerican Commission (Tracking 100 million years of biological symbioses in fossil termites - N. Robin).

\section{Authors contributions}

NR and PB have collaboratively drafted the manuscript and performed amber specimen preparation and imaging. PB provided the report of the Cambay amber synclusion of springtails with an alate termite. Drawings and schemes were done by NR. CDH provided novel observations on hidden cases of modern springtail associations and supervised taxonomic assignments. All authors read and approved the final manuscript.

\section{Funding}

This work has been achieved along a 2018-2019 Fulbright Non-US Visiting Scholar Program (National Program) of the French-American Commission granted to N. Robin (Tracking 100 million years of biological symbioses in fossil termites).

\section{Availability of data and materials}

Not applicable

\section{Ethics approval and consent to participate}

Not applicable

\section{Consent for publication}

Not applicable

\section{Competing interests}

The authors declare that they have no competing interests.

\section{Author details}

'Department of Biological Sciences, New Jersey Institute of Technology, Newark, NJ, USA. ${ }^{2}$ MECADEV, UMR 7179 CNRS/Museum national d'Histoire naturelle, Paris, France. ${ }^{3}$ Division of Invertebrate Zoology, American Museum of Natural History, New-York, New-York, USA.

\section{Received: 26 June 2019 Accepted: 18 October 2019}

\section{Published online: 21 November 2019}

\section{References}

1. Zeh DW, Zeh JA. Failed predation or transportation? Causes and consequences of phoretic behavior in the pseudoscorpion Dinocheirus arizonensis (Pseudoscorpionida: Chernetidae) (Pseudoscorpionida: Chernetidae). J Insect Behav. 1992;5:37-49.

2. Binns ES. Phoresy as migration - some functional aspects of phoresy in mites. Biol Rev. 1982;57:571-620.

3. Aguiar N, Bührnheim P. Phoretic pseudoscorpions associated with flying insects in Brazilian Amazonia. J Arachnol. 1998;26:452-9.

4. Farish DJ, Axtell RC. Phoresy redefined and examined in Macrocheles muscaedomesticae (Acarina: Macrochelidae). Acarologia. 1971;8:16-29.

5. Lesne P. Moeurs du "Limosina sacra", phénomènes de transport mutuel chez les animaux articulés, origine du parasitisme chez les insectes diptères. Bull la Société Entomol Fr. 1896;162-5.

6. Clausen CP. Phoresy among entomophagous insects. Annu Rev Entomol. 1976;21:343-68.

7. Poinar GOJ, Grimaldi DA. Fossil and extant macrochelid mites (Acari: Macrochelidae) phoretic on drosophilid flies (Diptera: Drosophilidae). J New York Entomol Soc. 2013;98:88-92.

8. Robin N, Charbonnier S, Bartolini A, Petit G. First occurrence of encrusting nubeculariids (foraminifera) on a mobile host (Crustacea, Decapoda) from the upper Jurassic Eichstätt Lagerstätte, Germany: a new possible relation of phoresy. Mar Micropaleontol. 2013.

9. Robin N, Béthoux O, Sidorchuk E, King A, Sidorchuk E, Cui $Y$, et al. A carboniferous mite on an insect reveals the antiquity of an inconspicuous interaction. Curr Biol. 2016;26:1376-82.

10. Scourfield DJ. The oldest known fossil insect (Rhyniella praecursor Hirst \& Maulik) - further details from additional specimens. Proc Linn Soc. 1940;152:113-31.
11. Whalley P, Jarzembowski EA. A new assessment of Rhyniella, the earliest known insect, from the Devonian of Rhynie. Scotland Nature. 1981;291:317

12. Little C. The colonisation of land: origins and adaptations of terrestrial animals: Cambridge University Press; 1983.

13. Rusek J. Biodiversity of Collembola and their functional role in the ecosystem. Biodivers Conserv. 1998;7:1207-19.

14. Rapoport EH. The geographical distribution of Neotropical and Antarctic Collembola. Pacific Insects Monogr. 1971;25 iv:99-118.

15. Hawes TC, Worland MR, Convey P, Bale JS. Aerial dispersal of springtails on the Antarctic peninsula: implications for local distribution and demography. Antarct Sci. 2007;19:3-10.

16. Dunger W, Schulz H-J, Zimdars B. Colonization behaviour of Collembola under different conditions of dispersal. Pedobiologia (Jena). 2002;46:316-27.

17. Moore PD. Springboards for springtails. Nature. 2002;418:381.

18. Reynolds DR, Reynolds AM, Chapman JW. Non-volant modes of migration in terrestrial arthropods. Anim Migr. 2014;2.

19. Coulson SJ, Hodkinson ID, Webb NR, Harrison JA. Survival of terrestrial on and arthropods in seawater: for trans-oceanic implications dispersal. Funct Ecol. 2002;16:353-6.

20. Hawes TC, Worland MR, Bale JS, Convey P. Rafting in Antarctic collembola. J Zool. 2008;274:44-50.

21. Riek EF. An entomobryid collembolan (Hexapoda: Collembola) from the lower Permian of southern Africa. Palaeontol Africana. 1976;19:141-3.

22. Poinar GOJ. Phoresy. In: Boucot AJ, Poinar GOJ, editors. Fossil behavior compendium. Taylor and Boca Raton, USA: CRC Press Taylor and Francis Group; 2010. p. 181-184.

23. Grünemaier M. Phoretic springtail (Collembola: Sminthuridae) on a false blister beetle (Coleoptera: Oedemeridae) in Eocene Baltic amber. Palaeodiversity. 2016;9:9-13.

24. Penney D, McNeil A, Green DI, Bradley RS, Jepson JE, Withers PJ, et al. Ancient ephemeroptera-collembola symbiosis fossilized in amber predicts contemporary phoretic associations. PLoS One. 2012;7:7-10.

25. Börner C. Zur Kenntnis der Apterygoten-Fauna von Bremen und de Nachbardistrikte. Beitrag zur einer Apterygoten-Fauna Mitteleuropas. Abhandlungen Hrsg des Naturwissenschaftlichen Verein zu Bremen. 1901;17:1-40

26. Börner C. Phylogenetic systematics of the higher taxa of Symphypleona (Insecta, Entognatha, Collembola) Apterygota. In: Dallai R, editor. Second international symposium on Apterygota. Siena, Italy: University of Siena; 1986. p. 307-311.

27. Börner C. Das System der Collembolen nebst Beschreibung neuer Collembolen des Hamburger Naturhistorischen Museums. Mitteilungen aus den Naturhistorischen Museum Hambg. 1906:23:147-88.

28. Massoud Z, Betsch J-M. Etude sur les Insectes Collemboles II. - Les caractères sexuels secondaires des antennes des Symphypléones. Rev d'Ecologie Biol du Sol. 1972;IX:55-97.

29. Krishna K, Grimaldi DA. Diverse Rhinotermitidae and Termitidae (Isoptera) in Dominican amber. Am Museum Novit. 2009;3640:1-48.

30. Mayer H. Zur Biologie und Ethologie einheimischer Collembolen. Zoo Jahrbücher Abteilung für Syst Geogr und Biol der Tiere. 1957;85:501-71.

31. Blancquaert JP. Mating behaviour in some Sminthurididae (Collembola) with reference tothe systematics of Symphypleona. Pedobiologia (Jena). 1981.

32. Mutt M. Collembola in amber from the Dominican Republic. Proc Entomol Soc Washingt. 1983;85:575-87.

33. Perez-Gelabert DE. Arthropods of Hispaniola (Dominican Republic and Haiti); 2008.

34. Penney D. Dominican amber. In: Penney $D$, editor. Biodiversity of fossils in amber. Manchester, United-Kingdom: Siri Scientific Press; 2010. p. 22-41.

35. Engel MS, Grimaldi DA, Krishna K. Termites (Isoptera): their phylogeny, classification, and rise to ecological dominance. Am Musem Novit. 2009; 3650:1-27.

36. Grimaldi D, Agosti D. A formicine in New Jersey cretaceous amber (Hymenoptera: Formicidae) and early evolution of the ants. Proc Natl Acad Sci. 2000;97:13678-83.

37. LaPolla JS, Dlussky GM, Perrichot V. Ants and the fossil record. Annu Rev Entomol. 2011;58:609-30.

38. Perrichot V, Lacau S, Néraudeau D, Nel A. Fossil evidence for the early ant evolution. Naturwissenschaften. 2008;95:85-90. 
39. Barden P, Grimaldi DA. Adaptive radiation in socially advanced stem-group ants from the cretaceous. Curr Biol. 2016;26:515-21.

40. Nalepa CA. Origin of termite eusociality: trophallaxis integrates the social, nutritional and microbial environments. Ecol Entomol. 2015::323-35.

41. Evangelista DA, Wipfler B, Be O, Donath A, Fujita M, Kohli MK, et al. An integrative phylogenomic approach illuminates the evolutionary history of cockroaches and termites (Blattodea). Proc R Soc B Biol Sci. 2019;286:20182076.

42. Johnson NF, Triplehorn C. Borror and Delong's introduction to the study of insects. Belmont, USA: Thomson Brooks/Cole; 2005.

43. Gärdenfors U, Wilander P. Ecology and phoretic habits of Anthrenochernes stellae (Pseudoscorpionida, Chernetidae). Bull Br Arachnol Soc. 1995;10:28-30.

44. Macchioni F, Magi M, Mancianti F, Perrucci S. Phoretic association of mites and mallophaga. Parasite. 2005;12:277-9.

45. Townsend VR Jr, Proud DN, Moore MK, Tibbetts JA, Burns JA, Hunter RK, et al. Parasitic and phoretic mites associated with Neotropical harvestmen from Trinidad. West Indies Ann Entomol Soc Am. 2008;101:1026-32.

46. Beaty LE, Esser HJ, Miranda R, Norton RA. First report of phoresy by an oribatid mite (Trhypochthoniidae: Archegozetes magnus) on a frog (Leptodactylidae: Engystomops pustulosus). Int J Acarol. 2013;39:325-6.

47. Bretfeld G. Sminthuridida. In: Dunger W, editor. Synopses on Palaearctic Collembola, volume 2. Symphypleona. Abhandlungen und Berichte des Naturkundemuseums Görlitz, Volume 71. Görlitz, Germany: Staatliches Museum für Natürkunde Das Museum; 1999. p. 29-61.

48. Farrow RA, Greenslade P. A vertical migration of Collembola. Entomologist 1992;111:38-45.

49. Johnson DL, Wellington A. Dispersal of the collembolan, Folsomia candida Willem, as a function of age. Can J Zool. 1983;61:2534-8.

50. Freeman JA. Occurence of Collembola in air. Proc R Entomol Soc London, Ser A, Gen Entomol. 1952;27:28.

51. Richards WR. Generic classification, evolution, and biogeography of the Sminthuridae of the world (Collembola). Mem Entomol Soc Canada. 1968; 100(Supplement S53):3-54.

52. Sánchez-García A, Engel MS. Long-term stasis in a diverse fauna of early cretaceous springtails (Collembola: Symphypleona). J Syst Palaeontol. 2016; 15:513-37.

53. Silvestri F. Termitofili raccolti dal prof. K. Escherick in Ceylan. Zool Jahrbücher Syst. 1911;30:401-18.

54. Handschin E. Neue myrmecophile und termitophile Collembolenformen aus Süd-Amerika. Neue Beiträge zur Syst Insektenkd. 1924;3:1-26.

55. Delamare Deboutteville CL. Recherches sur les Collemboles termithophiles et myrmécophiles. Arch Zool Expérimentale Générale. 1948;85:261-425.

56. Moser JC, Blomquist SR. Phoretic arthropods of the red imported fire ant in Central Louisiana. Ann Entomol Soc Am. 2011;104:886-94.

57. Caillon P. Dans l'intimité des Collemboles. Insectes. 2014;174:11-5.

58. Jacquemart S. Un collembole nouveau de Papouasie, Actaletes vangoethemi sp n associé au bernard l'ermite Coenobita rugosa Milne Edwards Ann la Société R Zool Belgique 1979;109:67-75.

59. Mari Mutt JA. A Caribbean male Coenaletes, and new records from the Dominican Republic and St. Croix, USVI (Hexapoda: Collembola: Coenaletidae). Caribb J Sci. 1994;30:272-4.

60. Bellinger PF. A new family of Collembola (Arthropoda, Tracheata). Caribb J Sci. 1985;21:117-23.

61. Maldonado-Vargas C, Palacios-Vargas JG. Microartrópodos asociados con el cangrejo ermitaño Coenobita clypeatus. In: Memorias del XXXIV Congreso Nacional de Entomología; 1999. p. 57-61

62. Palacios-Vargas JG, Cutz LQ, Maldonado C. Redescription of the male of Coenaletes caribaeus (Collembola: Coenaletidae) associated with hermit crabs (Decapoda: Coenobitidae). Ann Entomol Soc Am. 2000;93:194-7.

63. Williams JD, McDermott JJ. Hermit crab biocoenoses: a worldwide review of the diversity and natural history of hermit crab associates. J Exp Mar Bio Ecol. 2004;305:1-128.

64. Palacios-Vargas JG. Los ácaros y los colémbolos asociados a cangrejos ermitaños y su similitud con las pulgas y piojos humanos. Dugesiana. 2007;14:23-6.

65. Conway JR. Notes on Repletes, myrmecophiles, and predators of honey ant nests (Myrmecocystus mexicanus) (Hymenoptera: Formicidae) in Arizona. J New York Entomol Soc. 1990;98:103-7.

66. Cushing PA. Description of the spider Masoncus pogonophilus (Araneae, Linyphiidae), a harvester ant myrmecophile. J Arachnol. 1995;23:55-9.

67. Thibaud J. Collembola class ("springtails"). In: Ghabbour S, editor. Animal resource and diversity in Africa. Cairo, Egypt: UNESCO-EOL; 1997. p. 2. Collembola.
68. Bar-On YM, Phillips R, Milo R. The biomass distribution on earth. Proc Natl Acad Sci. 2018;115:6506-11.

69. Fittkau AEJ, Klinge H. On biomass and trophic structure of the central Amazonian rain forest ecosystem. Biotropica. 1973;5:2-14.

70. Engel MS, Grimaldi DA, Krishna K. Termites (Isoptera): their phylogeny, classification and rise to ecological dominance. Am Museum Novit. 2009;3650:1-27.

71. Grimaldi D, Agosti D. A formicine in New Jersey cretaceous amber (Hymenoptera: Formicidae) and early evolution of the ants. Proc Natl Acad Sci. 2002;97:13678-83.

72. Lucky A, Trautwein MD, Guénard BS, Weiser MD. Dunn RR. Tracing the rise of ants - out of the ground. 2013;8:6-13.

73. Nalepa CA. Ancestral transfer of symbionts between cockroaches and termites: an alternative hypothesis. Proc R Soc B Biol Sci. 1991;246:191-5.

74. Nalepa CA, Bignell DE, Bandi C. Detritivory, coprophagy, and the evolution of digestive mutualisms in Dictyoptera. Insect Soc. 2001;48:194-201.

75. Evans TA. The influence of soil heterogeneity on exploratory tunnelling by the subterranean termite Coptotermes frenchi (Isoptera: Rhinotermitidae). Bull Entomol Res. 2003;93:413-23.

76. Maruyama M, Akino T, Hashim R, Komatsu T. Behavior and cuticular hydrocarbons of myrmecophilous insects (Coleoptera: Staphylinidae; Diptera: Phoridae; Thysanura) associated with Asian Aenictus army ants (Hymenoptera; Formicidae). S Sociobiology. 2009;54:19-35.

77. Rettenmeyer CW. The behavior of Thysanura found with army ants. Ann Entomol Soc Am. 1963;56:170-4.

78. Evans TA, Lo N, Bourguignon T, Šobotník J, Sillam-Dussès D, Roisin Y Oceanic dispersal, vicariance and human introduction shaped the modern distribution of the termites Reticulitermes, Heterotermes and Coptotermes. Proc R Soc B Biol Sci. 2016;283:20160179.

79. Messenger MT, Mullins AJ. New flight distance recorded for Coptotermes formosanus (Isoptera: Rhinotermitidae). Florida Entomol. 2006:88:99-100.

80. Wurst E, Berghoff SM, Sendova-Franks AB, Rettenmeyer CW, Franks NR, Ebermann E. Symbionts of societies that fission: mites as quests or parasites of army ants. Ecol Entomol. 2009:34:684-95.

81. Wheeler WM. The ants of the Baltic amber. Schriften der Phys Gesellschaft zu Königsb. 1915;55:1-142.

82. Dunlop JA, Kontschán J, Walter DE, Perrichot V, Walter DE, Perrichot V, et al. An ant-associated mesostigmatid mite in Baltic amber. Biol Lett. 2014;10 September:20140531.

83. Eickwort G. Associations of mites with social insects. Annu Rev Entomol. 1990;35:469-88.

84. Samsinák K. Termitophile Milben aus der V. R China I Acarioidea Reiehenbachia. 1965;5:291-4

85. Grasse P-P. Termitologia: Comportement-Socialité-Ecologie-EvolutionSystématique. Paris: Masson; 1986.

86. Phillipsen WT, Coppel HC. Acotyledon formosani sp. n. Associated with the formosan subterranean termite, Coptotermes formosanus Shiraki (Acarina: acaridae-Isoptera: Rhinotermitidae). J Kansas Entomol Soc. 1977:50:399-409.

87. Phillipsen WT, Coppel HC. Histiostoma formosana sp. n. Associated with the formosan subterranean termite, Coptotermes formosanus Shiraki, (Acarina: Anoetidae-Isoptera: Rhinotermitidae). J Kansas Entomol Soc. 1977;50:496-502.

88. Phillipsen WT, Coppel HC. Uroobovella formosana sp. n. Associated with the Formosan subterranean termite, Coptotermes formosanus Shiraki (Acarina: Uropodidae: Isoptera: Rhinotermitidae). J Kansas Entomol Soc. 1978;51:22-7.

89. Wang C, Powell JE, O'Connor B. Mites and nematodes associated with three subterranean termite species (Isoptera). The Florida Enromologist. 2002:85:499-506.

90. Silva AF, Pinto ZT, Caetano RL, Carriço C, Sato TP, Amorim M, et al. Bulb mites Rhizoglyphus echinopus (Fumouze and Robin) associated with subterranean termite (Isoptera) in Brazil. Entomo Bras. 2016;9:65-8.

91. Lubbock J. Monograph of the Collembola and Thysanura. London, UnitedKingdom: Ray Society; 1873.

92. Gronenberg W. Fast actions in small animals: springs and click mechanisms J Comp Physiol A Sensory, Neural, Behav Physiol. 1996:178:727-34.

93. Deharveng L. Recent advances in Collembola systematics. Pedobiologia (Jena). 2004:48:415-33.

\section{Publisher's Note}

Springer Nature remains neutral with regard to jurisdictional claims in published maps and institutional affiliations. 